\title{
Advanced weight-bearing mat exercises combined with functional electrical stimulation to improve the ability of wheelchair-dependent people with spinal cord injury to transfer and attain independence in activities of daily living: a randomized controlled trial
}

\author{
Mostafa Rahimi $^{1} \cdot$ Giti Torkaman ${ }^{1} \cdot$ Mojdeh Ghabaee $^{2} \cdot$ Ali Ghasem-Zadeh $^{3}$
}

Received: 22 January 2019 / Revised: 1 July 2019 / Accepted: 3 July 2019 / Published online: 16 July 2019

(c) The Author(s), under exclusive licence to International Spinal Cord Society 2019

\begin{abstract}
Study design Randomized controlled trial.

Objective To determine the effects of advanced weight-bearing mat exercises (AWMEs) with/without functional electrical stimulation (FES) of the quadriceps and gastrocnemius muscles on the ability of wheelchair-dependent people with spinal cord injury (SCI) to transfer and attain independence in activities of daily living (ADLs).

Setting An outpatient clinic, Iran.

Methods People with traumatic chronic paraplegia $(N=16)$ were randomly allocated to three groups. The exercise group (EX; $N=5$ ) performed AWMEs of quadruped unilateral reaching and tall-kneeling for 24 weeks ( 3 days/week). Sessions were increased from $10 \mathrm{~min}$ to $54 \mathrm{~min}$ over the 24-week period. The exercise-FES group (EX + FES; $N=5$ ) performed AWMEs simultaneously with FES of the quadriceps and gastrocnemius muscles. The control group performed no exercise and no FES $(N=6)$. The primary outcomes were the total Spinal Cord Independence Measure-III (SCIM-III) to reflect independence with ADL, and the sum of the four SCIM-III transfer items to reflect ability to transfer. There were six other outcomes.

Results The mean $(95 \% \mathrm{CI})$ between-group differences of the four transfer items of the SCIM-III for the EX vs. control group was 1.8 points (0.2-3.4), and for the EX + FES vs. control group was 2 points (0.4-3.6). The equivalent differences for the total SCIM-III scores were 2.7 points $(-0.6-6.0)$ and 4.1 points $(0.8-7.4)$, respectively. There were no significant between-group differences for any other outcomes.

Conclusions Advanced weight-bearing mat exercises improve the ability of wheelchair-dependent people with SCI to transfer and attain independence in ADL.
\end{abstract}

\section{Introduction}

Spinal cord injury (SCI) affects people's abilities to perform activities of daily living (ADLs) by increasing the time

Giti Torkaman

torkamg@modares.ac.ir

1 Department of Physiotherapy, Faculty of Medical Sciences, Tarbiat Modares University, Tehran, Iran

2 Iranian Center of Neurological Research, Neuroscience Institute, Tehran University of Medical Sciences, Tehran, Iran

3 Departments of Medicine and Endocrinology, Austin Health, The University of Melbourne, Melbourne, VIC, Australia required for personal care (bathing, dressing, and grooming), reducing mobility (walking and transferring), as well as negatively affecting individuals' functional independence and quality of life [1-4]. Transferring is important for community integration and wheelchair-dependent people with SCI use transfers during their ADLs [5, 6]. Pivot transfers (wheelchair to bed, toilet seat, car seat, bath chair, and vice versa) are typical movements and are normally performed 14 to 20 times a day [7-9]. Wheelchair users with SCI have been found to have decreased or absent trunk control, leading to poor sitting balance and stability, which in turn may cause falls during transfers [10-12]. Specific types of exercises that target upper extremity strength and trunk control are widely provided to people with SCI to improve their ability to transfer [13-15]. 
Fig. 1 CONSORT diagram depicting participant flow

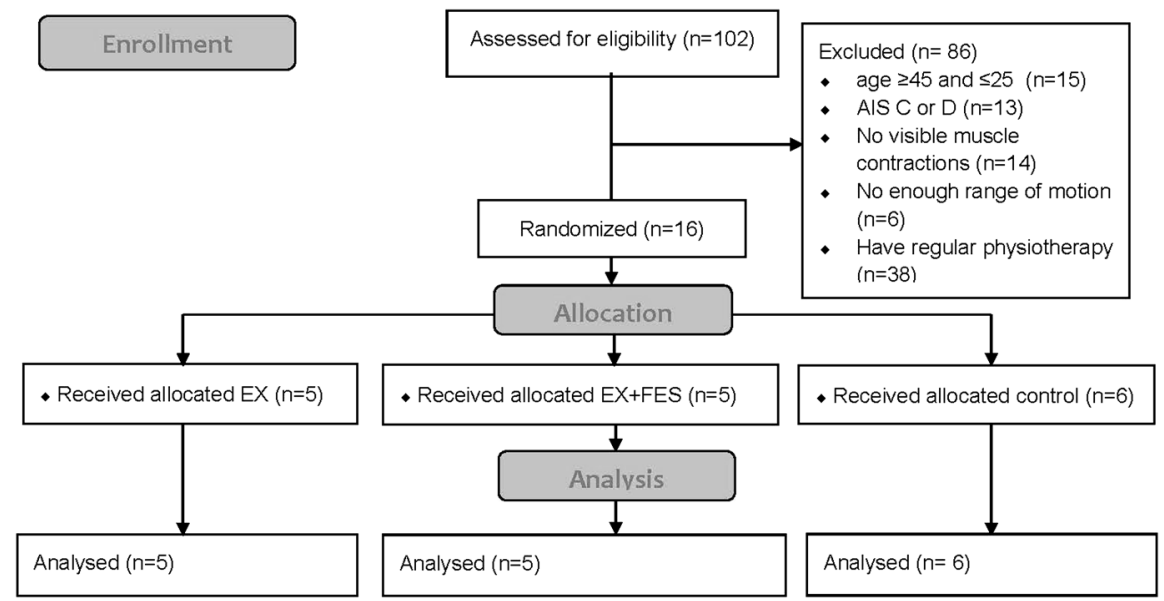

Martin and Kessler [16] state that advanced weightbearing mat exercises (AWMEs) of quadruped unilateral reaching and tall-kneeling have widespread functional benefits in people with SCI. They, along with Sullivan [17], argue that: quadruped unilateral reaching exercises develop upper extremity strength and coordination and improve the ability to transfer from the wheelchair to the floor; and tall-kneeling exercises promote trunk control, which can be used as a transitional position from the floor back into a wheelchair and is a preambulation activity. Despite the widespread use of these exercises in rehabilitation clinics, no study has investigated the effectiveness of AWMEs on the ability of people with SCI to transfer and attain independent with ADLs.

Functional electrical stimulation (FES) is a rehabilitation technique applied to produce functional movements such as leg flexion/extension, standing, walking, grasping, cycling, and rowing in individuals with SCI [18, 19]. It is paired with task-specific practice to facilitate exercise [20, 21]. Some studies indicated that FES on the lower limbs assists transfers in people with SCI [22, 23]. Thus, herein it was assumed that, the contraction of the extensor and flexor knee muscles with FES induces anterior and posterior weight shift, increasing forward and backward perturbations during AWMEs, thereby improving the ability to transfer and perform ADLs. This randomized clinical trial was designed to investigate the effects of a 24-week AWMEs program with/without FES of the quadriceps and gastrocnemius muscles on the ability of people with SCI to perform transfer and attain independence in ADLs.

\section{Methods}

\section{Participants}

A consecutive sample of 102 people with SCI from Iranian SCI associations responded to advertising notices posted via
Telegram messenger between October 2016 and February 2017. All 102 people were screened and 16 people were included in the study. The inclusion criteria were traumatic SCI, chronic SCI (over 1 year from injury), paraplegia (T2-T12) with an American Spinal Injury Association (ASIA) impairment scale grade (AIS) A or B, (based on the International Standard For Neurological Classification of SCI (ISNCSCI)), no voluntary movement in the lower limbs, aged between 25 and 45 years, responding to FES in the quadriceps and gastrocnemius muscles (visible muscle contractions) [24], enough range of motion in the hip, knee, and ankle joints to do the AWMEs, medically stable, and not receiving regular physiotherapy (including AWMEs and electrotherapy) in the previous 6 months. The exclusion criteria were unwillingness to participate or cooperate, and complications such as fracture, infection, or pregnancy. All participants were followed for 24 weeks (Fig. 1). The study was conducted in an outpatient clinic (Iran) and ended in August 2017. This study was registered in the Iranian Registry of Clinical Trials, Ministry of Health and Medical Education Department as \#IRCT201304084952N3 before randomization of participants. All participants consented to participate after the study protocol was explained.

\section{Procedure}

Baseline assessments were performed by a trained physiotherapist and included collecting data on age, gender, height, weight, medical history, ISNCSCI, AIS, range of motion of the hip, knees, and ankle joints, and the ability of the quadriceps and gastrocnemius muscles to respond to FES. Participants were randomly allocated to the exercise group $(\mathrm{EX} ; N=5)$, exercise-FES group $(\mathrm{EX}+\mathrm{FES} ; N=5)$, and control group $(\mathrm{N}=6)$. Concealment of allocation and assignment was performed by an independent person by blocking randomization using sealed, opaque, and stapled envelopes. 
The EX and EX + FES performed AWMEs of quadruped unilateral reaching and tall-kneeling 3 days per week for 24 weeks (a total of 72 sessions) at the outpatient clinic under supervision of a trained physiotherapist. In the first 2 weeks, each exercise was performed for $5 \mathrm{~min}$. Every 2 weeks, the training time was progressively increased by $2 \mathrm{~min}$ ( $2 \mathrm{~min}$ for each exercise and $4 \mathrm{~min}$ in total), so by the $23 \mathrm{rd}$ and 24 th week, it equated to $27 \mathrm{~min}$ per day for each exercise with a total of 54 min per day for two exercises. In the EX + FES, FES was applied for the quadriceps and gastrocnemius muscles on both lower extremities simultaneously with AWMEs (stimulation started at the beginning of each exercise and continued until the end). Participants in the intervention groups performed their daily activities as before and did not receive any other intervention. The control group consisted of participants who received no exercise and FES during the study period and they continued with their usual daily activities.

While exercising, participants were allowed to rest as needed, but they were required to complete the full training time in each session. At the beginning of each session, the participants performed 5 min of warm-up exercises including stretching of hamstrings, gluteus maximus, ankle plantar flexors, and hip rotators.

\section{Advanced AWMEs}

The quadruped unilateral reaching exercises consisted of the following steps (Fig. 2):

- Step 1. The participant was asked to assume a four-point position with the help of a physiotherapist if necessary.

- Step 2. Once the participant was able to maintain the quadruped position, he/she practiced anterior, posterior, right, and left weight shifts, as well as arching the back

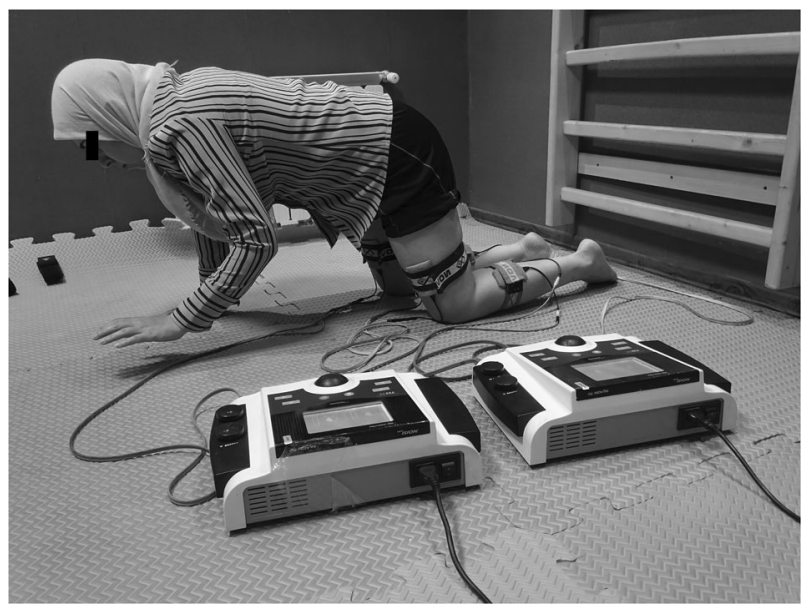

Fig. 2 Quadruped unilateral reaching exercise combined with FES of the quadriceps and gastrocnemius muscles and letting it sag. When the participant was able to maintain his/her balance during weight shifting, alternating isometrics (isometric contractions rhythmically alternating from one side of joint to other side in one or more plane) and rhythmic stabilization (isometric contractions occurring in all three planes simultaneously) were practiced with the assistance of the physiotherapist.

- Step 3. The participant was asked to practice unilateral reaching with one upper extremity while maintaining his/her balance [16, 17].

The tall-kneeling exercises consisted of the following steps (Fig. 3):

- Step 1. The participant was asked to assume a quadruped or side-seating position.

- Step 2. Using a ladder fixed on the wall, the participant pulled up to a tall-kneeling position, hips forward, while resting on the iliofemoral (Y) ligaments.

- Step 3. The participant tried to maintain his/her balance in this position.

- Step 4. The participant was asked to practice the alternating isometrics, rhythmic stabilization, and reaching activities while maintaining his/her balance [16, 17].

\section{Functional electrical stimulation}

A 733X-model electrical stimulator (Novin Co., Esfahan, Iran) was used to induce contractions of the quadriceps and gastrocnemius muscles (Fig. 2). Surface rubber electrodes of $6 \times 8 \mathrm{~cm}$ in size were strapped bilaterally over the

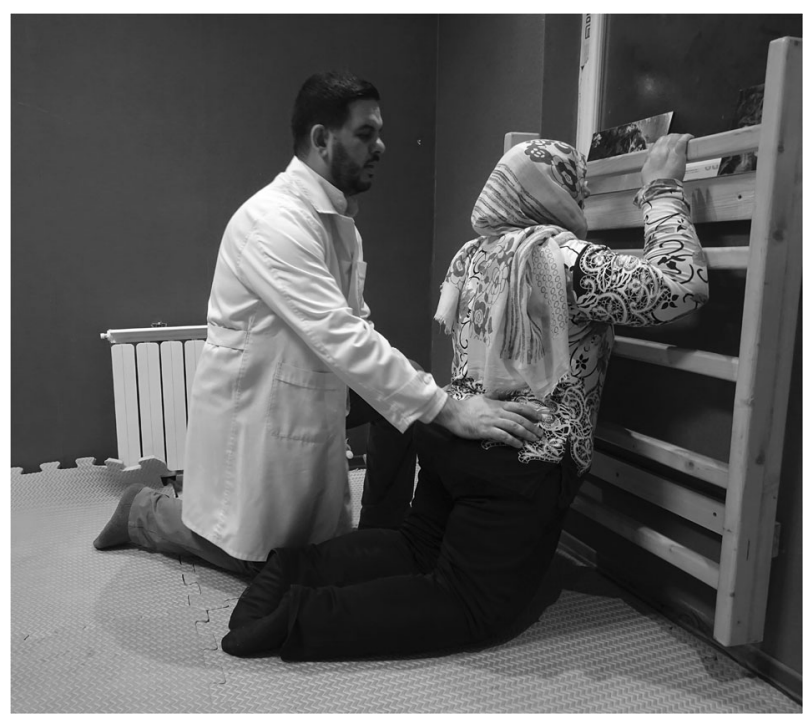

Fig. 3 Tall-kneeling exercise. Alternating isometrics and rhythmic stabilization are practiced by the physiotherapist 
quadriceps and gastrocnemius muscles [25]. Rectangular pulses were applied with a pulse width of $400 \mu$ s, and a frequency of $40 \mathrm{~Hz}$ at an on/off cycle of $5 / 10 \mathrm{~s}$. The stimulation amplitude was adjusted individually from 20 to $200 \mathrm{~mA}$ to produce a visible contraction [24].

\section{Outcome measures}

All outcome measures were taken before and after the 24-week intervention by a blinded physiotherapist. The primary outcomes were the total Spinal Cord Independence Measure-III (SCIM-III) to reflect independence with ADL (max score of 100 points), and the sum of the four SCIM-III transfer items to reflect ability to transfer (max score of 7 points). There were six other outcomes. All outcomes were collected at the beginning and end of the study. The details are outlined below.

\section{Spinal Cord Independence Measure-III}

The SCIM-III was used to measure independence with ADL and ability to transfer. The SCIM-III is a disability scale specifically designed for people with SCI to evaluate functional changes in a person's daily life [26]. This instrument comprises 19 items in three subscales: (i) selfcare (0-20); (ii) respiration and sphincter management (0-40); and (iii) mobility (0-40). The total score ranges from 0 to 100 , with a higher score reflecting greater independence with ADLs. To assess the ability to perform transfers, four transfer items from the mobility subscale were used and tallied into one score (0-7). This included the bed-wheelchair transfer (0-2); wheelchair-toilet-tub transfer $(0-2)$; wheelchair-car transfer (0-2); and ground-wheelchair transfer $(0-1)$. So a total of six outcomes were derived from all the SCIM-III for analyses, namely:

- The total SCIM-III (max score of 100 points).

- The sum of the four SCIM-III transfer items (max score of 7 points).

- The self-care subscale (max score of 20 points).

- The respiratory item (max score of 10 points).

- The sphincter items (max score of 30 points).

- The mobility subscale except transfer items (max score of 33 points).

The Persian version of the SCIM-III was used as a selfreport for this study. Its reliability and validity have been established in a previous study [27].

\section{Time in quadruped/kneeling}

The maximal amount of time a participant was able to maintain quadruped unilateral reaching and tall-kneeling positions without FES was measured using a digital timer.
These measures were used to reflect changes in endurance, strength and coordination of the upper limb and trunk muscles (above the level of injury), postural stability, and dynamic control of the trunk $[16,17]$.

Participants were asked to stay in the quadruped position while reaching out unilaterally without assistance. They were told to maintain this position as long as possible. This was performed twice with a 2-min interval for rest, and the longest time was recorded. If the participant was unable to perform unilateral reaching in the quadruped position, the quadruped position alone was replaced with this move. Thus, the participant was asked to assume a quadruped position without help twice with a 2-min interval for rest, and the longest time was recorded. Similarly, the longest placement time in the tall-kneeling position was measured. After 24 weeks only one repetition was recorded if a participant stated he/she had reached his/her maximum capability and was capable of maintaining the position for a long period of time.

\section{Statistical analysis}

Statistical analysis was performed using SPSS software (version 22, IBM Corp., Armonk, NY, USA). Descriptive statistics were used for the demographic and clinical data and expressed as means and standard deviations. The Shapiro-Wilk test was used to assess the assumption of normality. In each group, the scores of the SCIM-III (items and total score) and the amount of time spent in quadruped unilateral reaching and tall-kneeling (time in quadruped/kneeling) at baseline and after 24 weeks of intervention were compared using the paired-samples $t$-test. Analysis of variance (one-way ANOVA) was used along with the post hoc Tukey test to compare the difference in SCIM-III (items and total score) and time in quadruped/kneeling parameters between the groups. A $P$-value of $<0.05$ was considered as statistically significant.

\section{Results}

Among 102 people assessed for study eligibility, 16 people with T5-T12 AIS A were recruited and randomly allocated to three groups: $\mathrm{EX}(N=5), \mathrm{EX}+\mathrm{FES}(N=5)$, and control $(N=6)$. The sample size was that which could be realistically achieved within a 4-month recruitment period. All participants were included in the analysis with respect to the groups they were assigned to (Fig. 1). The demographic and clinical characteristics of the study population are shown in Table 1 .

\section{Spinal Cord Independent Measure-III}

Changes in the total score of the SCIM-III, and the subscores and item scores of the SCIM-III before and after 
Table 1 Demographics and clinical characteristics of study population

\begin{tabular}{llll}
\hline & $\begin{array}{l}\text { EX } \\
(N=5)\end{array}$ & $\begin{array}{l}\text { EX+FES } \\
(N=5)\end{array}$ & $\begin{array}{l}\text { Control group } \\
(N=6)\end{array}$ \\
\hline $\begin{array}{l}\text { Gender } \\
\text { Female/Male }\end{array}$ & $5 / 0^{\mathrm{a}}$ & $4 / 1$ & $4 / 2$ \\
Age (year) & $37(4.5)^{\mathrm{b}}$ & $35(5.7)$ & $39(3.2)$ \\
BMI $\left(\mathrm{kg} / \mathrm{m}^{2}\right)$ & $23(5.5)$ & $30(8.9)$ & $26(6.8)$ \\
Duration of & $13(5.7)$ & $14(7.0)$ & $13(8.4)$ \\
injury (year) & & & 3 \\
$6-10$ & 2 & 1 & 1 \\
$11-15$ & 2 & 2 & 0 \\
$16-20$ & 0 & 1 & 2 \\
$21-25$ & 1 & 1 & 6 \\
AIS A & 5 & 5 &
\end{tabular}

$E X$ exercise group, $E X+F E S$ exercise with functional electrical stimulation group, BMI body mass index, ISNCSCI International Standard for Neurological Classification of SCI, AIS ASIA impairment scale grade

${ }^{a}$ Number of participants

${ }^{\mathrm{b}}$ Mean (SD)

24 weeks of intervention are shown in Table 2 . The mean (95\% CI) between-group differences of these scores are shown in Table 3. For the EX, the four transfer items improved 1.8 points (95\% CI, 0.2-3.4) compared to the control group, but the SCIM-III total score difference was not significant (95\% CI, $-0.6-6.0)$. For EX + FES, the four transfer items and the SCIM-III total score improved 2 points (95\% CI, 0.4-3.6) and 4.1 points (95\% CI, 0.8-7.4), respectively, compared to the control group. There was no significant difference in the four transfer items $(95 \% \mathrm{CI}$, $-1.9-1.6)$ or the SCIM-III total score (95\% CI, $-4.8-2.0)$ between two intervention groups.

\section{Time in quadruped/kneeling}

Changes in the time in quadruped/kneeling before and after 24 weeks of intervention are shown in Table 2. The mean (95\% CI) between-group differences of the time in quadruped/kneeling are shown in Table 3. For the EX, the time spent in quadruped unilateral reaching and tall-kneeling positions improved $15 \mathrm{~min}$ (95\% CI, 4.6-26) and $22 \mathrm{~min}$ (95\% CI, 6.6-37), respectively, compared to the control group. For the EX + FES, the time spent in quadruped unilateral reaching and tall-kneeling positions increased $16 \mathrm{~min}$ (95\% CI, 5.3-26) and $30 \mathrm{~min}$ (95\% CI, 15-45), respectively, compared to the control group. There was no significant difference in the time spent in quadruped unilateral reaching $(95 \% \mathrm{CI},-12-10)$ and tall-kneeling positions $(95 \% \mathrm{CI},-24-8.0)$ between the two intervention groups.
Table 2 Changes in SCIM-III scores and time in quadruped/kneeling before and after 24 weeks of intervention

\begin{tabular}{|c|c|c|c|}
\hline SCIM-III (score) & $\begin{array}{l}\mathrm{EX} \\
(N=5)\end{array}$ & $\begin{array}{l}\mathrm{EX}+\mathrm{FES} \\
(N=5)\end{array}$ & $\begin{array}{l}\text { Control group } \\
(N=6)\end{array}$ \\
\hline \multirow{3}{*}{$\begin{array}{l}\text { Time in quadruped/ } \\
\text { kneeling (min) }\end{array}$} & Pre & Pre & Pre \\
\hline & Post & Post & Post \\
\hline & Post - pre & Post - pre & Post - pre \\
\hline \multirow{3}{*}{$\begin{array}{l}\text { Four transfer items, } \\
17 \text { points }\end{array}$} & $4.2(1.9)$ & $4.6(2.3)$ & $5.2(1.7)$ \\
\hline & $5.8(1.6)$ & $6.4(1.3)$ & $5.0(1.5)$ \\
\hline & $1.6(1.1)^{*}$ & $1.8(1.3)^{*}$ & $-0.2(0.4)$ \\
\hline \multirow{3}{*}{$\begin{array}{l}\text { Self-care subscale, } \\
/ 20 \text { points }\end{array}$} & $20(0.0)$ & $20(0.0)$ & $20(0.0)$ \\
\hline & $20(0.0)$ & $20(0.0)$ & $20(0.0)$ \\
\hline & $0.0(0.0)$ & $0.0(0.0)$ & $0.0(0.0)$ \\
\hline \multirow{3}{*}{$\begin{array}{l}\text { Respiration item, } \\
/ 10 \text { points }\end{array}$} & $10(0.0)$ & $10(0.0)$ & $10(0.0)$ \\
\hline & $10(0.0)$ & $10(0.0)$ & $10(0.0)$ \\
\hline & $0.0(0.0)$ & $0.0(0.0)$ & $0.0(0.0)$ \\
\hline \multirow{3}{*}{$\begin{array}{l}\text { Sphincter items, } \\
\text { /30 points }\end{array}$} & $17.6(7.4)$ & $18.6(3.7)$ & $19.7(2.5)$ \\
\hline & $17.8(7.5)$ & $20.2(3.5)$ & $19.7(2.5)$ \\
\hline & $0.2(0.4)$ & $1.6(1.8)$ & $0.00(0.0)$ \\
\hline \multirow{3}{*}{$\begin{array}{l}\text { Mobility subscale } \\
\text { (except transfer items), } \\
\text { /33 points }\end{array}$} & $11.2(1.3)$ & $11.6(0.5)$ & $11.5(0.8)$ \\
\hline & $11.8(0.4)$ & $12(0.0)$ & $11.3(0.8)$ \\
\hline & $0.6(0.9)$ & $0.4(0.5)$ & $-0.2(0.4)$ \\
\hline \multirow{3}{*}{$\begin{array}{l}\text { Total SCIM-III, } \\
/ 100 \text { points }\end{array}$} & $63.0(9.6)$ & $64.8(5.8)$ & $66.3(4.5)$ \\
\hline & $65.4(8.7)$ & $68.6(3.4)$ & $66(4.2)$ \\
\hline & $2.4(1.5)^{*}$ & $3.8(3.3)$ & $-0.3(0.8)$ \\
\hline \multirow{3}{*}{$\begin{array}{l}\text { Quadruped unilateral } \\
\text { reaching }\end{array}$} & $12(4.9)$ & $10(8.0)$ & $15(13)$ \\
\hline & $26(6.0)$ & $26(9.2)$ & $14(11)$ \\
\hline & $14(9.6)^{*}$ & $16(6.9)^{*}$ & $-1(1.6)$ \\
\hline \multirow[t]{3}{*}{ Tall-kneeling } & $7(4.4)$ & $6(9.9)$ & $11(14)$ \\
\hline & $30(13)$ & $36(16)$ & $12(15)$ \\
\hline & $23(10)^{*}$ & $30(13)^{*}$ & $1(3.2)$ \\
\hline
\end{tabular}

$A D L s$ activities of daily living, $E X$ exercise group, $E X+F E S$ exercise with functional electrical stimulation group. Mean (SD)

$* P<0.05$

Additional bone density data were also collected as part of this study but have not yet analyzed. They will be published in the future.

\section{Discussion}

This study investigated the effect of 24-week AWMEs with/ without FES of the quadriceps and gastrocnemius muscles on the ability to transfer and attain independence in ADLs in people with SCI. Few studies have reported on the effects of exercise on the ability of people with SCI to perform transfer and attain independence in ADLs [28-30], and no study has reported on the effects of AWMEs in combination with FES. Advanced AWMEs are a relatively inexpensive 
Table 3 Comparison of the mean between-group differences of SCIMIII scores and time in quadruped/kneeling

\begin{tabular}{llll}
\hline SCIM-III (score) & EX vs. Control & $\begin{array}{l}\text { EX }+ \text { FES vs. } \\
\text { Control } \\
\text { Mime in quadruped/ }\end{array}$ & $\begin{array}{l}\text { EX vs. EX }+ \\
\text { FES }\end{array}$ \\
$\begin{array}{l}\text { kneeling (min) } \\
\text { Mean }(95 \% \mathrm{CI})\end{array}$ & $\begin{array}{l}\text { Mean }(95 \% \mathrm{CI}) \\
\text { P-value }\end{array}$ & $P$-value & $P$-value \\
\hline $\begin{array}{l}\text { Four transfer items, } \\
\text { /7 points }\end{array}$ & $1.8(0.2-3.4)$ & $2.0(0.4-3.6)$ & $-0.2(-1.9-1.6)$ \\
Sphincter items, & $0.03^{*}$ & $0.02^{*}$ & 0.95 \\
/30 points & $0.2(-1.5-1.9)$ & $1.6(-0.1-3.3)$ & $-1.4(-3.1-0.3)$ \\
Mobility subscale & 0.95 & 0.06 & 0.12 \\
(except transfer items), & $0.8(-0.2-1.8)$ & $0.6(-0.4-1.6)$ & $0.2(-0.9-1.3)$ \\
/33 points & 0.15 & 0.33 & 0.88 \\
Total SCIM-III, & $2.7(-0.6-6.0)$ & $4.1(0.8-7.4)$ & $-1.4(-4.8-2.0)$ \\
/100 points & 0.11 & $0.01^{*}$ & 0.55 \\
Quadruped unilateral & $15(4.6-26)$ & $16(5.3-26)$ & $-1(-12-10)$ \\
reaching & $0.006^{*}$ & $0.004^{*}$ & 0.98 \\
Tall-kneeling & $22(6.6-37)$ & $30(15-45)$ & $-8(-24-8.0)$ \\
& $0.006^{*}$ & $0.001^{*}$ & 0.41 \\
\hline
\end{tabular}

Self-care subscale and respiration item were not included in the table because post score-pre score (post-pre, Table 2) was 0 in the three groups

$A D L s$ activities of daily living, $E X$ exercise group, $E X+F E S$ exercise with functional electrical stimulation group, $C I$ confidence interval

$* P<0.05$

form of therapy compared to training with special auxiliary devices such as FES cycling and rowing. They are also more feasible as they can be practiced independently in different places such as at home and while traveling. In addition, quadruped unilateral reaching and tall-kneeling exercises take people out of the seated position. This may help them attain a healthier lifestyle because prolonged sitting is an independent health risk factor contributing to mortality [31, 32].

After training, the participants in both intervention groups showed improved ability to perform transfers (to wheelchair, car seat, and toilet-tub) than the control group as reflected in the four transfer items of the SCIM-III. This is in line with previous research indicating improvements in the ability of people with SCI to transfer following therapeutic exercise alone [7, 16] and in combination with FES $[23,33]$. Exercises have been shown as an effective means to increase upper extremity strength, trunk control, and sitting balance in people with SCI [12, 34, 35]. Seemingly, quadruped unilateral reaching and tall-kneeling exercises improved transfer ability in similar ways. We did not find any significant differences between the two intervention groups for any outcomes. However, nor did we rule out the possibility of a difference indicating that our failure to find a difference could be due to the small sample size.

In the EX + FES, participants showed higher independence in ADLs than the controls as reflected in the SCIMIII total scores, indicating that AWMEs along with FES of the quadriceps and gastrocnemius muscles can increase independence with ADLs in people with SCI. This is in line with previous research showing that performing exercise along with FES improves performance of ADLs in these people [25, 36]. This could be due to the fact that FES of the quadriceps and gastrocnemius muscles increases forward and backward perturbation by increasing knee extension and flexion torque during exercise. As a result, increased muscle effort in the upper extremity and trunk (above the lesion level) is required to control balance. This may improve the ability to transfer and perform ADLs in people with SCI. For the EX, independence did not significantly increase in relation to the performance of ADLs.

Many of items of the SCIM-III, including self-care, respiration, mobility (in bed, indoors, for moderate distances, and outdoors), and stair management, may have been insensitive to changes in ADL for those with chronic wheelchair-dependent paraplegia. This may explain the lack of significant improvement in ADLs in the EX. Previous studies found similar limitations in the SCIM for people with thoracic SCI [37, 38].

The EX and EX + FES showed significant increases in the amount of time spent in quadruped unilateral reaching and tall-kneeling compared to the control group. Possibly, AWMEs increased the time spent in these positions due to an improvement in physical parameters such as upper extremity and trunk muscle endurance and strength, postural stability, and dynamic control of the trunk [16, 17]. Previous researchers have shown the effectiveness of exercise along with FES on these types of physical attributes in these people [39-41]. No significant differences were found between the two intervention groups on this outcome, but again this may be attributed to the small sample size. During the exercises, some participants complained of pain in the wrist, which was resolved after a brief rest. There was no report of problems in the performance of ADLs.

The present study had three limitations. Firstly, the study had a small sample size, which could be the reason why transfer ability and amount of time spent in the positions were not significantly higher for the EX + FES compared to the EX. Secondly, we did not use a direct and objective measure of upper extremity, trunk, and knee strength. Thirdly, it was not possible to determine whether or not FES alone improved participants' independence with ADL and ability to transfer because we did not include a group that received FES alone. Fourthly, we relied on self-report for SCIM-III scores. Participants were not blinded and therefore those in the two interventions groups might have overestimated their own abilities.

In conclusion, the results of the present study indicate that AWMEs improve independence with ADL and ability to transfer in people with SCI who are wheelchair 
dependent. However, these findings now need to be confirmed in a larger study with outcome measures that do not rely on self-report.

\section{Data archiving}

The datasets generated and/or analyzed during the current study are available from the corresponding author on reasonable request.

Acknowledgements We gratefully acknowledge all participants who participated in this study.

Funding This project was supported by a grant from Medical Sciences Faculty of Tarbiat Modares University, Tehran, Iran.

Author contributions MR was responsible for designing and planning the study, data collection, analysis, and interpretation, and writing the report. GT was responsible for designing and planning the study, analysis and interpretation of the results, and revision of the manuscript critically for important intellectual content. MG contributed to the neurological and related clinical conception and design. AG-Z contributed to the conception and design. All authors read and approved the final manuscript.

\section{Compliance with ethical standards}

Conflict of interest The authors declare that they have no conflict of interest.

Ethics The Research Ethics Committee of Tarbiat Modares University (Tehran, Iran) approved the study protocol \#52D/5326. We certify that all applicable institutional and governmental regulations concerning the ethical use of human volunteers were followed during the course of this research.

Publisher's note: Springer Nature remains neutral with regard to jurisdictional claims in published maps and institutional affiliations.

\section{References}

1. Scott JM, Warburton DER, Williams D, Whelan S, Krassioukov A. Challenges, concerns and common problems: physiological consequences of spinal cord injury and microgravity. Spinal Cord. 2011;49:4-16.

2. Rivers CS, Fallah N, Noonan VK, Whitehurst DG, Schwartz CE, Finkelstein JA, et al. Health conditions: effect on function, healthrelated quality of life, and life satisfaction after traumatic spinal cord injury. A prospective observational registry cohort study. Arch Phys Med Rehabil. 2018;99:443-51.

3. Hetz SP, Latimer AE, Ginis KA. Activities of daily living performed by individuals with SCI: relationships with physical fitness and leisure time physical activity. Spinal Cord. 2009;47:550-4.

4. Sezer N, Akkuş S, Uğurlu FG. Chronic complications of spinal cord injury. World J Orthop. 2015;6:24-33.

5. Carpenter C, Forwell SJ, Jongbloed LE, Backman CL. Community participation after spinal cord injury. Arch Phys Med Rehabil. 2007;88:427-33.

6. Nelson AL, Groer S, Palacios P, Mitchell D, Sabharwal S, Kirby $\mathrm{RL}$, et al. Wheelchair-related falls in veterans with spinal cord injury residing in the community: a prospective cohort study. Arch Phys Med Rehabil. 2010;91:1166-73.

7. You JS, Kim YL, Lee SM. Effects of a standard transfer exercise program on transfer quality and activities of daily living for transfer-dependent spinal cord injury patients. J Phys Ther Sci. 2017;29:478-83.

8. Gagnon D, Nadeau S, Noreau L, Eng JJ, Gravel D. Trunk and upper extremity kinematics during sitting pivot transfers performed by individuals with spinal cord injury. Clin Biomech. 2008;23:279-90.

9. Gagnon D, Koontz AM, Brindle E, Boninger ML, Cooper RA. Does upper-limb muscular demand differ between preferred and nonpreferred sitting pivot transfer directions in individuals with a spinal cord injury? J Rehabil Res Dev. 2009;46:1099-108.

10. Desroches G, Gagnon D, Nadeau S, Popovic MR. Effects of sensorimotor trunk impairments on trunk and upper limb joint kinematics and kinetics during sitting pivot transfers in individuals with a spinal cord injury. Clin Biomech. 2013;28:1-9.

11. Milosevic M, Masani K, Kuipers MJ, Rahouni H, Verrier MC, McConville KM, et al. Trunk control impairment is responsible for postural instability during quiet sitting in individuals with cervical spinal cord injury. Clin Biomech. 2015;30:507-12.

12. Seong Choe H, Min DK, Ahn J. Effects of anterior weight-shifting methods on sitting balance in wheelchair-dependent patients with spinal cord injury. J Phys Ther Sci. 2018;30:393-7.

13. Jacobs PL. Effects of resistance and endurance training in persons with paraplegia. Med Sci Sports Exerc. 2009;41:992-7.

14. Paralyzed Veterans of America Consortium for Spinal Cord Medicine. Preservation of upper limb function following spinal cord injury: a clinical practice guideline for healthcare professionals. J Spinal Cord Med. 2005;28:434-70.

15. Tweedy SM, Beckman EM, Geraghty TJ, Theisen D, Perret C, Harvey LA, et al. Exercise and Sports Science Australia (ESSA) position statement on exercise and spinal cord injury. J Sci Med Sport. 2017;20:108-15.

16. Martin ST, Kessler M. Neurological intervention for physical therapy. 3rd ed. Saunders: Elsevier; 2015. p. 431-3.

17. Sullivan PE, Markos PD. Clinical decision making in therapeutic exercise. 1st ed. Norwalk: Appleton \& Lange; 1994. p. 45. 73-75, 210

18. Martin R, Sadowsky C, Obst K, Meyer B, McDonald J. Functional electrical stimulation in spinal cord injury: from theory to practice. Top Spinal Cord Inj Rehabil. 2012;18:28-33.

19. Ho CH, Triolo RJ, Elias AL, Kilgore KL, DiMarco AF, DPhil $\mathrm{KB}$, et al. Functional electrical stimulation and spinal cord injury. Phys Med Rehabil Clin N Am. 2014;25:631-54.

20. Gorgey AS, Lawrence J. Acute responses of functional electrical stimulation cycling on the ventilation-to- $\mathrm{CO} 2$ production ratio and substrate utilization after spinal cord injury. PM R. 2016;8:225-34.

21. Fornusek C, Davis GM, Beak I. Stimulation of shank muscles during functional electrical stimulation cycling increases ankle excursion in individuals with spinal cord injury. Arch Phys Med Rehabil. 2012;93:1930-6.

22. Lopes AC, Ochoa-Diaz C, Baptista R, Fonseca L, Fattal C, Azevedo Coste $\mathrm{C}$, et al. Electrical stimulation to reduce the overload in upper limbs during sitting pivot transfer in paraplegic: a preliminary study. Eur J Transl Myol. 2016;26:278-82.

23. Jovic J, Azevedo Coste C, Fraisse P, Henkous S, Fattal C. Coordinating upper and lower body during FES-assisted transfers in persons with spinal cord injury in order to reduce arm support. Neuromodulation. 2015;18:736-43.

24. Ryan TE, Brizendine JT, Backus D, McCully KK. Electrically induced resistance training in individuals with motor complete spinal cord injury. Arch Phys Med Rehabil. 2013;94: 2166-73. 
25. Sadowsky CL, Hammond ER, Strohl AB, Commean PK, Eby SA, Damiano DL, et al. Lower extremity functional electrical stimulation cycling promotes physical and functional recovery in chronic spinal cord injury. J Spinal Cord Med. 2013;36: 623-31.

26. Catz A, Itzkovich M, Tesio L, Biering-Sorensen F, Weeks C, Laramee MT, et al. A multicenter international study on the Spinal Cord Independence Measure, version III: Rasch psychometric validation. Spinal Cord. 2007;45:275-91.

27. Saberi H, Vosoughi F, Derakhshanrad N, Yekaninejad M, Khan $\mathrm{ZH}$, Kohan $\mathrm{AH}$, et al. Development of Persian version of the Spinal Cord Independence Measure III assessed by interview: a psychometric study. Spinal Cord. 2018;56:980-6.

28. Rice LA, Smith I, Kelleher AR, Greenwald K, Hoelmer C, Boninger ML. Impact of the clinical practice guideline for preservation of upper limb function on transfer skills of persons with acute spinal cord injury. Arch Phys Med Rehabil. 2013;94:1230-46.

29. Harvey LA, Lin CW, Glinsky JV, De Wolf A. The effectiveness of physical interventions for people with spinal cord injuries: a systematic review. Spinal Cord. 2009;47:184-95.

30. Calder A, Nunnerley J, Mulligan H, Ahmad Ali N, Kensington G, McVicar T, et al. Experiences of persons with spinal cord injury undertaking a physical activity programme as part of the SCIPA 'full-on' randomized controlled trial. Disabil Health J. 2018;11:267-73.

31. Gorgey AS. Exercise awareness and barriers after spinal cord injury. World J Orthop. 2014;5:158-62.

32. Krause JS, Broderick L. Patterns of recurrent pressure ulcers after spinal cord injury: identification of risk and protective factors 5 or more years after onset. Arch Phys Med Rehabil. 2004;85:1257-64.

33. Triolo RJ, Bailey SN, Miller ME, Lombardo LM, Audu ML. Effects of stimulating hip and trunk muscles on seated stability, posture, and reach after spinal cord injury. Arch Phys Med Rehabil. 2013;94:1766-75.

34. Herzog T, Swanenburg J, Hupp M, Mittaz Hager AG. Effect of indoor wheelchair curling training on trunk control of person with chronic spinal cord injury: a randomised controlled trial. Spinal Cord Ser Cases. 2018;4:26.

35. Gagnon DH, Roy A, Gabison S, Duclos C, Verrier MC, Nadeau S. Effects of seated postural stability and trunk and upper extremity strength on performance during manual wheelchair propulsion tests in individuals with spinal cord injury: an exploratory study. Rehabil Res Pract. 2016;2016:6842324.

36. Deley G, Denuziller J, Casillas JM, Babault N. One year of training with FES has impressive beneficial effects in a 36-yearold woman with spinal cord injury. J Spinal Cord Med. 2017;40:107-12.

37. van Hedel HJ, Curt A. Fighting for each segment: estimating the clinical value of cervical and thoracic segments in SCI. J Neurotrauma. 2006;23:1621-31.

38. Aidinoff E, Front L, Itzkovich M, Bluvshtein V, Gelernter I, Hart J, et al. Expected Spinal Cord Independence Measure, third version, scores for various neurological levels after complete spinal cord lesions. Spinal Cord. 2011;49:893-6.

39. Bélanger M, Stein RB, Wheeler GD, Gordon T, Leduc B. Electrical stimulation: can it increase muscle strength and reverse osteopenia in spinal cord injured individuals? Arch Phys Med Rehabil. 2000;81:1090-8.

40. Shields RK, Dudley-Javoroski S. Musculoskeletal adaptations in chronic spinal cord injury: effects of long-term soleus electrical stimulation training. Neurorehabil Neural Repair. 2007; 21:169-79.

41. Fornusek C, Davis GM, Russold MF. Pilot study of the effect of low-cadence functional electrical stimulation cycling after spinal cord injury on thigh girth and strength. Arch Phys Med Rehabil. 2013;94:990-3. 